\title{
PYRUVATE METABOLISM IN BOAR SPERMATOZOA
}

\author{
D. E. BROOKS* AND T. MANN \\ Agricultural Research Council, Unit of Reproductive Physiology and Biochemistry, \\ University of Cambridge, Cambridge
}

(Received 6th Fuly 1972)

\begin{abstract}
Summary. Boar spermatozoa utilize pyruvate efficiently both anaerobically and aerobically. Pyruvate metabolism, in marked contrast to fructolysis, continues in spermatozoa immobilized by cold shock. Sperm cytoplasmic droplets alone do not metabolize pyruvate. Carbon dioxide, lactate, acetate, succinate and acetoacetate were identified as anaerobic products of pyruvate metabolism; the ratio between pyruvate utilized and lactate and acetate formed did not fit into the stoichiometry of a simple dismutation. Carbon dioxide and lactate were formed from pyruvate aerobically. The rate of pyruvate disappearance, as well as the percentage of pyruvate converted to lactate, were higher aerobically than anaerobically. Very little acetoacetate was utilized by boar spermatozoa aerobically. Lactate was oxidized but at a much lower rate than pyruvate. Acetate $\left(0.18 \mu \mathrm{mol} / 10^{9}\right.$ cells $)$ was extracted from exhaustively washed spermatozoa; this acetate is assumed to be derived from acetyl compounds of the sperm cells.
\end{abstract}

\section{INTRODUGTION}

It is generally held that lactate formed from the anaerobic breakdown of exogenous sugar by the spermatozoa of various species does not account quantitatively for all the sugar used up, but different authors vary in their estimates of this discrepancy (Melrose \& Terner, 1953; Mann, 1964; Rothschild, 1964; Graves, Lodge \& Salisbury, 1966; Nevo, Polge \& Frederick, 1970). Among other organic acids that have been identified as products of glycolysis in ram and bull spermatozoa is acetic acid (Flipse \& Almquist, 1955; Graves et al., 1966; Scott, Voglmayr \& Setchell, 1967; Wales \& Humphries, 1969), but it is conceivable that acetic acid is formed when some of the glycolytically produced pyruvic acid undergoes an oxidoreductive dismutation yielding lactic acid and carbon dioxide. Such a dismutation was first described in certain anaerobically metabolizing tissues by Krebs \& Johnson (1937) and was later postulated for bull spermatozoa (Melrose \& Terner, 1953; Terner, 1962). In bacteria, pyruvate metabolism was shown by Korkes, del Campillo, Gunsalus \& Ochoa (1951) to involve two NAD-dependent reactions:

* Present address: Department of Anatomy, Harvard Medical School, 25 Shattuck Street, Boston, Massachusetts 02115, U.S.A. 


$$
\begin{aligned}
& \text { Pyruvate }+\mathrm{NADH}+\mathrm{H}^{+} \longrightarrow \text { Lactate }+\mathrm{NAD}^{+} \\
& \text {Pyruvate }+\mathrm{NAD}^{+}+\mathrm{CoASH} \longrightarrow \text { Acetyl-CoA }+\mathrm{CO}_{2}+\mathrm{NADH}+\mathrm{H}^{+} \\
& \text {Sum }: 2 \text { Pyruvate }+\mathrm{CoASH} \longrightarrow \text { Lactate }+ \text { Acetyl-CoA }+\mathrm{CO}_{2}
\end{aligned}
$$

The aim of the present study has been to establish whether the oxidoreductive dismutation represents the main pathway for pyruvate metabolism in spermatozoa, and at the same time, to identify additional metabolites that may arise from the breakdown of pyruvate. Boar spermatozoa were chosen for the experiments partly because little is known about their action on pyruvate, but also because their carbohydrate metabolism differs from that of bull or ram spermatozoa, in that they have a low glycolytic activity and maintain their motility more efficiently under aerobic than anaerobic conditions (Aalbers, Mann \& Polge, 1961; Mann, 1964; Nevo et al., 1970).

\section{MATERIALS AND METHODS}

\section{Chemicals}

Sodium pyruvate was obtained from Koch-Light Laboratories, Colnbrook, Bucks.; D lithium lactate, $\mathrm{L}(+)$ lactic acid, lithium acetoacetic acid, 3-hydroxybutyric acid and phenazine methosulphate were supplied by Sigma (London) Chemical Co., London, S.W.6. NAD ${ }^{+}$, NADH, lactate dehydrogenase (EC 1.1.1.27), 3-hydroxybutyrate dehydrogenase (EC 1.1.1.30), glutamic dehydrogenase (EC 1.4.1.2) and malate dehydrogenase (EC 1.1.1.37) were supplied by Boehringer Corp. (London) Ltd, London, W.5. Peroxidase RZ=1 (EG 1.11.1.7), fermcozyme 653 AM (glucose oxidase EC 1.1.3.4) and guaiacum were obtained from Hughes and Hughes (Enzymes) Ltd, Bromford Essex. $\left[1-{ }^{14} \mathrm{C}\right]$ pyruvic acid $\left(14.4 \mathrm{mCi} / \mathrm{mmol}\right.$ as the $\mathrm{Na}^{+}$salt $),\left[2-{ }^{14} \mathrm{C}\right]$ pyruvic acid $\left(13.6 \mathrm{mCi} / \mathrm{mmol}\right.$ as the $\mathrm{Na}^{+}$salt $)$and $\mathrm{NaH}^{14} \mathrm{CO}_{3}(60 \mathrm{mCi} / \mathrm{mmol})$ were obtained from The Radiochemical Centre, Amersham, Bucks. Diazald (Nmethyl-N-nitroso-p-toluenesulphonamide) was purchased from Ralph $\mathrm{N}$. Emanuel Ltd, Wembley, Middlesex. All other chemicals were of analytical reagent grade where available and all solvents were redistilled before use.

Succinic dehydrogenase was prepared from beef heart mitochondria by the method of Bernath \& Singer (1962). The enzyme was prepared in a soluble form and purified as far as the elution from the calcium phosphate gel; it was stored frozen under $\mathrm{N}_{2}$.

\section{Semen}

The sperm-rich fraction of boar ejaculates was collected by artificial vagina (Glover \& Mann, 1954). This fraction represents the middle portion of the boar ejaculate; its volume was usually 30 to $50 \mathrm{ml}$, containing about $10^{9}$ spermatozoa/ $\mathrm{ml}$. Gelatinous material was removed by straining the semen through two layers of muslin. The spermatozoa were concentrated by centrifugation at $600 \mathrm{~g}$ for $10 \mathrm{~min}$ and washed twice by resuspension and centrifugation in a Ringerphosphate medium of $\mathrm{pH} 7.4\left(119.3 \mathrm{~mm}-\mathrm{NaCl}, 4.8 \mathrm{~mm}-\mathrm{KCl}, 1.2 \mathrm{~mm}-\mathrm{KH}_{2} \mathrm{PO}_{4}\right.$, $1.2 \mathrm{~mm}-\mathrm{MgSO}_{4}, 2.4 \mathrm{~mm}-\mathrm{NaHCO}_{3}, 41.7 \mathrm{~mm}$-sodium phosphate). The spermatozoa were finally resuspended in Ringer-phosphate to approximately $10^{9}$ spermatozoa $/ \mathrm{ml}$. Sperm concentration was determined using a Spekker absorp- 
tiometer (Hilger \& Watts Ltd, London, N.W.1) by the method of Bishop, Campbell, Hancock \& Walton (1954). Separation of spermatozoa from their accompanying cytoplasmic droplets was carried out for us by the method described by Harrison \& White (1972).

Incubations were set up in a thermostatically controlled water bath maintained at either 25 or $37^{\circ} \mathrm{C}$. Aerobic samples were shaken in air. Anaerobic samples were usually incubated in Thunberg tubes which had been four times evacuated and filled with $\mathrm{N}_{2}$ passed through copper filings heated at 400 to $450^{\circ} \mathrm{C}$.

\section{Radioactive counting}

Radioactivity was determined in a Packard liquid-scintillation spectrometer model 3380 fitted with an Absolute Activity Analyser calibrated to record d/min directly. Three counting media were employed. For non-polar samples, $5 \mathrm{ml}$ toluene containing $4 \mathrm{~g}$ PPO (2,5-diphenyloxazole) and $0.3 \mathrm{~g}$ POPOP (1,4bis-(5-phenyloxazol-2-yl)-benzene) per litre were added as the scintillator medium. For polar samples, $5 \mathrm{ml}$ of a $2: 1(\mathrm{v} / \mathrm{v})$ mixture of the non-polar system described above and Triton X-100 were used. For counting the radioactive carbon dioxide which had been trapped in 2-methoxyethanol: ethanolamine $(2: 1, \mathrm{v} / \mathrm{v}), 1 \mathrm{ml}$ of this trapping system was added to $5 \mathrm{ml}$ of toluene:2-methoxyethanol $(2: 1, \mathrm{v} / \mathrm{v})$ containing $5.5 \mathrm{~g}$ PPO/litre (Jeffay \& Alvarez, 1961).

\section{Collection of ${ }^{14} \mathrm{CO}_{2}$}

Incubations with $\left[{ }^{14} \mathrm{C}\right]$ pyruvic acid were carried out in manometer flasks containing the incubation mixture in the main compartment and filter paper soaked with $0.2 \mathrm{ml} 10 \%(\mathrm{w} / \mathrm{v}) \mathrm{KOH}$ in the centre well. The flasks were sealed with rubber 'subra-seal' caps through which a needle could be inserted for evacuating and gassing with $\mathrm{N}_{2}$, and for injecting either substrate or the deproteinizing agent. Incubations were terminated by adding $1 / 10$ vol. $25 \%$ $(\mathrm{w} / \mathrm{v})$ metaphosphoric acid, and the flasks were then shaken at $37^{\circ} \mathrm{C}$ for $20 \mathrm{~min}$ to ensure complete trapping of $\mathrm{CO}_{2}$ in the centre well. Next, the deproteinized incubation mixture was removed, and the flask rinsed out twice with water, before placing it inside a closed jar together with a scintillation vial containing $1 \mathrm{ml}$ 2-methoxyethanol: ethanolamine $(2: 1, \mathrm{v} / \mathrm{v})$ as trapping agent. The closed jar was designed so that $0.5 \mathrm{M}-\mathrm{H}_{2} \mathrm{SO}_{4}$ could be injected into the manometer flask and allowed to overflow into the alkali trap, but without any $\mathrm{CO}_{2}$ escaping from the jar. The jar was left at room temperature for $24 \mathrm{hr}$ and the scintillation vial was then removed for radioactivity counting. When a standard of $\mathrm{NaH}^{14} \mathrm{CO}_{3}$ was carried through the above procedure, the recovery of radioactivity was at least $98 \%$.

\section{Determination of metabolites}

For pyruvate determinations, a stock solution of pyruvate was standardized with lactate dehydrogenase, the assay being carried out spectrophotometrically in a cuvette containing $2 \mathrm{ml} 0.1 \mathrm{M}$-tris brought to $\mathrm{pH} 7.6$ with $\mathrm{M}-\mathrm{HCl}+0.1 \mathrm{ml}$ $5 \mathrm{~mm}-\mathrm{NADH}+0.9 \mathrm{ml}$ stock solution and water. Using the standard solution, pyruvate was determined in incubation mixtures by the method of Friedemann 
\& Haugen (1943), specific for pyruvic acid. Under the experimental conditions investigated, neither acetoacetate nor acetone interfered appreciably with the pyruvate determinations. Lactate was determined in metaphosphoric or perchloric acid extracts, by the method of Barker \& Summerson (1941); samples that had been incubated with fructose were first given treatment with copper sulphate and calcium hydroxide. Fructose was determined after precipitation with equal volumes of $5 \%(\mathrm{w} / \mathrm{v}) \mathrm{ZnSO}_{4} \cdot 7 \mathrm{H}_{2} \mathrm{O}$ and $0.15 \mathrm{~m}-\mathrm{Ba}(\mathrm{OH})_{2}$, by the method of Roe (1934) as adapted to semen by Mann (1948). Citrate was determined colorimetrically by the method of Perlman, Lardy \& Johnson (1944). Acetoacetate and 3-hydroxybutyrate were determined by means of 3hydroxybutyrate dehydrogenase (Williamson, Mellanby \& Krebs, 1962), with a final assay volume of $1 \mathrm{ml}$. For this assay, sperm suspensions were precipitated with $1 / 6$ vol. $18 \%(\mathrm{w} / \mathrm{w}) \mathrm{HClO}_{4}$; the supernatant from centrifugation was neutralized with $20 \%(\mathrm{w} / \mathrm{v}) \mathrm{KOH}$ and the $\mathrm{KClO}_{4}$ precipitate removed by centrifugation. Malate was determined by adding malate dehydrogenase to the assay system for 3-hydroxybutyrate. The method of Westerfeld (1945) was used for the detection of acetoin and diacetyl. Glucose was estimated with glucose oxidase (Morley, Dawson \& Marks, 1968). 2-Oxoglutarate was determined using glutamate dehydrogenase; the final concentrations in the $1-\mathrm{ml}$ reaction mixture were, $45 \mathrm{~mm}$-imidazole brought to $\mathrm{pH} 7.3$ with $\mathrm{m}-\mathrm{HCl}, 48 \mathrm{~mm}$-ammonium acetate, 1 mm-imidazole brought to $\mathrm{pH} 7.3$ with $\mathrm{M}-\mathrm{HCl}, 48 \mathrm{~mm}$-ammonium acetate, $1 \mathrm{~mm}$-EDTA and $0 \cdot 15 \mathrm{~mm}-\mathrm{NADH}$.

Volatile fatty acids were determined by gas-liquid chromatography after steam-distillation. The incubated suspension of spermatozoa was deproteinized with $1 / 10$ vol. $25 \%$ (w/v) metaphosphoric acid. The extract was brought to $\mathrm{pH}$ 3.0 with $\mathrm{M}-\mathrm{NaOH}$ and steam-distilled (Markham, 1942). The first $100 \mathrm{ml}$ of distillate were collected, adjusted to $\mathrm{pH} 11$ with $0.1 \mathrm{M}-\mathrm{NaOH}$, and brought to dryness in a rotary evaporator. The dry residue was taken up in a small volume of $10 \%$ (w/v) metaphosphoric acid and aliquots of the solution analysed by gasliquid chromatography, in a Pye-Unicam Series 104 gas chromatograph fitted with a flame-ionization detector. The volatile fatty acids were separated on a 1.5 -m all-glass column ( $4 \mathrm{~mm}$ internal diameter) of polyethyleneglycol $20 \mathrm{M}$ operated at $125^{\circ} \mathrm{C}$ with an argon flow rate of $50 \mathrm{ml} / \mathrm{min}$. Propionic acid was used as the internal recovery standard. Non-volatile organic acids were also separated by gas-liquid chromatography. For this purpose, the incubation mixtures were precipitated with metaphosphoric acid as described above. Samples $(5 \mathrm{ml})$ of the protein-free extract were extracted with 10 vols ether in a continuous extraction apparatus for $8 \mathrm{hr}$. The ether extract was dried overnight with anhydrous $\mathrm{Na}_{2} \mathrm{SO}_{4}$, filtered through a sintered glass funnel and its volume carefully reduced by distillation to about $1 \mathrm{ml}$. Methanol $(0.1 \mathrm{ml})$ was added and the methyl derivatives of the organic acids were prepared by bubbling diazomethane through the solution until it turned yellow. The diazomethane used for this purpose was generated from a solution of Diazald in ether reacting with methanol over $50 \%(\mathrm{w} / \mathrm{v}) \mathrm{KOH}$ in a microgenerator similar to that described by Roper \& Ma (1957). Excess diazomethane was removed by bubbling $\mathrm{N}_{2}$ through the ethereal solution containing the methyl derivatives of the organic acids. The volume was then adjusted to approximately $1 \mathrm{ml}$ with ether and 
aliquots were taken for gas-liquid chromatography. Separation was achieved on a 1.5-m all-glass column ( $4 \mathrm{~mm}$ internal diameter) of $10 \%(\mathrm{w} / \mathrm{w})$ polyethyleneglycoladipate with an argon flow rate of $50 \mathrm{ml} / \mathrm{min}$; the temperature was maintained at $50^{\circ} \mathrm{C}$ for $8 \mathrm{~min}$ after injection, followed by a rise of $3^{\circ} \mathrm{C} / \mathrm{min}$ to $180^{\circ} \mathrm{C}$. Salicylic acid was added to the original extract as an internal recovery standard; differences in detection response to different acids were taken into account. Combined gas-liquid chromatography and mass spectrometry of the methyl esters of organic acids was carried out at the Agricultural Research Council's Food Research Institute at Colney, Norfolk.

\section{Other techniques}

Sonic disruption of spermatozoa was carried out by subjecting $5-\mathrm{ml}$ aliquots of a suspension containing approximately $10^{9}$ spermatozoa $/ \mathrm{ml}$ to sonic vibration for 2 min at power setting 2 on an ultrasonicator (Kerry's Ultrasonics Ltd, Hitchin, Herts.); during sonication, the material was surrounded by iced water. This treatment effectively separated the sperm heads from the mid-pieces and tails, with some fragmentation of the tail and mid-piece portions. Cold-shock treatment was carried out as described by Mann \& Lutwak-Mann (1955) by running the sperm suspension down the inner surface of a test-tube kept at $0^{\circ} \mathrm{C}$.

Electrophoresis of organic acids was carried out on Whatman No. 1 paper under white spirit (BDH Chemicals Ltd, Poole, Dorset), with the voltage applied at $50 \mathrm{~V} / \mathrm{cm}$. Two buffer systems were used: (a) $0.05 \mathrm{M}$-acetic acid adjusted to $\mathrm{pH} 4.0$ with pyridine; and (b) $0.1 \mathrm{M}$-ammonium carbonate, $\mathrm{pH} 8.9$. Organic acids were located by spraying the dried papers with acetone: water $(9: 1, \mathrm{v} / \mathrm{v})$ containing $0.025 \%$ bromophenol blue. For electrophoretograms run in the alkaline system, the stain was altered to include $0.1 \%$ citric acid (Gross, 1958).

Succinate was identified by means of succinic dehydrogenase, the oxygen uptake being measured with an oxygen electrode (Rank Bros, Engineers, Bottisham, Cambs.), connected to a Servoscribe recorder (Smiths Industries, Wembley, Middlesex).

\section{RESULTS}

General features of pyruvate metabolism in boar spermatozoa

We have found that boar spermatozoa utilize pyruvate both in the absence and presence of oxygen, producing $\mathrm{CO}_{2}$, lactate, acetate, succinate and acetoacetate anaerobically, but only $\mathrm{CO}_{2}$ and lactate aerobically. As a preliminary to a detailed investigation of the anaerobic and aerobic metabolites, it was necessary first to clear up the following points.

When the rate of anaerobic utilization of pyruvate was compared with that of fructose, it was found that the rate of pyruvate metabolism markedly exceeded that of fructolysis. In three experiments with fresh suspensions of washed, fully motile boar spermatozoa, the rate of fructose utilization at $25^{\circ} \mathrm{C}$ was only $0.84 \mu \mathrm{mol} / 10^{9}$ spermatozoa/hr, as against $4.27 \mu \mathrm{mol}$ for pyruvate utilization (Table 1). 


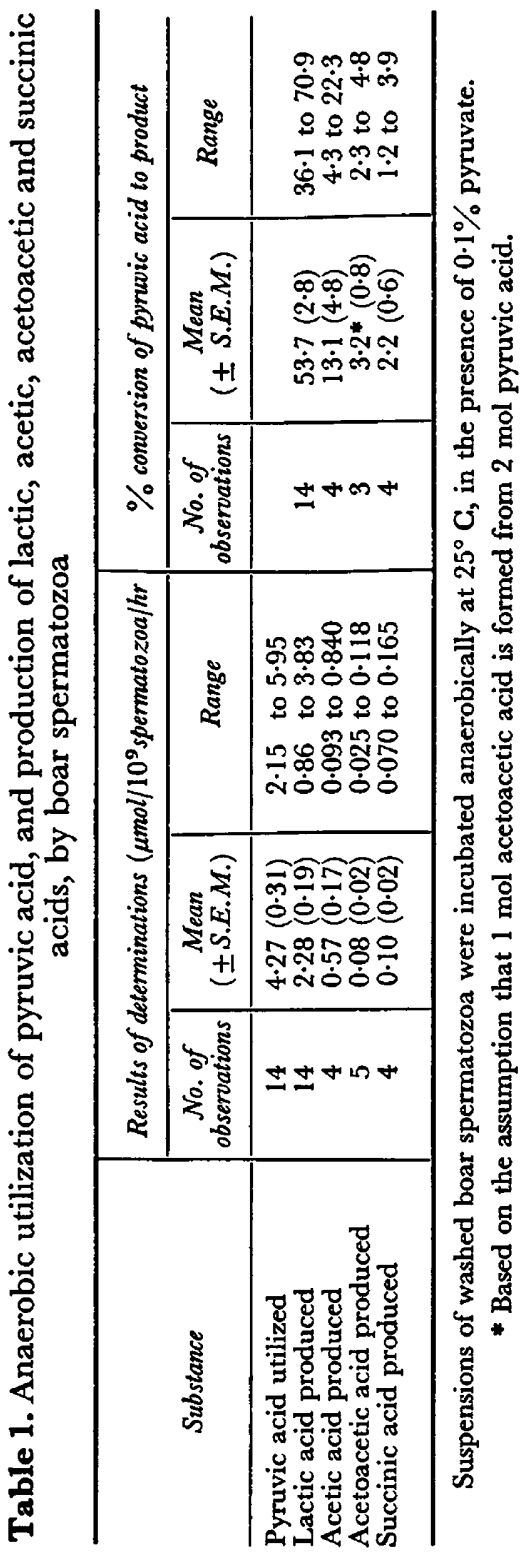


Immobilization of spermatozoa by cold shock, i.e. sudden exposure to $0^{\circ} \mathrm{C}$, severely curtailed their fructolysing capacity but had little effect on their ability to metabolize pyruvate. This is shown by the results of the four experiments recorded in Table 2; in fact, in one of the cold-shocked samples, the rate of pyruvate disappearance can be seen to have exceeded the control value.

Next, we examined the rôle of the cytoplasmic droplets. These, when separated from the spermatozoa, were found to be unable to utilize pyruvate or to produce lactate, whereas spermatozoa that had been separated from the droplets used up $1.73 \mu \mathrm{mol}$ pyruvate and produced $0.8 \mu \mathrm{mol}$ lactate $/ 10^{9} \mathrm{cells} / \mathrm{hr}$.

Table 2. The effect of cold-shock and sonic disruption of boar spermatozoa on anaerobic fructolysis and pyruvate metabolism

\begin{tabular}{|c|c|c|c|c|c|}
\hline Experiment & Sperm sample & $\begin{array}{l}\text { Fructose } \\
\text { utilized }\end{array}$ & $\begin{array}{c}\text { Pyruvate } \\
\text { utilized }\end{array}$ & $\begin{array}{c}\text { Lactate } \\
\text { produced }\end{array}$ & $\begin{array}{c}\text { Acetate } \\
\text { produced }\end{array}$ \\
\hline 1 & $\begin{array}{l}\text { Control } \\
\text { Cold-shocked }\end{array}$ & $\begin{array}{l}0.96 \\
0 \cdot 17\end{array}$ & & $\begin{array}{l}1.80 \\
0.29\end{array}$ & \\
\hline 2 & $\begin{array}{l}\text { Control } \\
\text { Cold-shocked }\end{array}$ & & $\begin{array}{l}3.94 \\
5.86\end{array}$ & $\begin{array}{l}2 \cdot 70 \\
2 \cdot 46\end{array}$ & $\begin{array}{l}0.88 \\
0.92\end{array}$ \\
\hline 3 & $\begin{array}{l}\text { Control } \\
\text { Cold-shocked } \\
\text { Sonicated }\end{array}$ & & $\begin{array}{l}4 \cdot 17 \\
2 \cdot 52 \\
0 \cdot 37\end{array}$ & $\begin{array}{l}1 \cdot 76 \\
0 \cdot 94 \\
0 \cdot 11\end{array}$ & \\
\hline \multirow[t]{3}{*}{4} & Control & 0.65 & \multirow{2}{*}{$2 \cdot 90$} & \multirow{3}{*}{$\begin{array}{l}1 \cdot 10 \\
1.35 \\
0.10 \\
1.35\end{array}$} & \multirow{3}{*}{$\begin{array}{l}0.08 \\
1 \cdot 15 \\
0 \\
1 \cdot 15\end{array}$} \\
\hline & & & & & \\
\hline & & & $2 \cdot 80$ & & \\
\hline
\end{tabular}

Washed suspensions of boar spermatozoa were incubated anaerobically at $25^{\circ} \mathrm{C}$ in the presence of $0.1 \%$ fructose or pyruvate. The results are expressed as $\mu \mathrm{mol} / 10^{9}$ spermatozoa/hr.

Lastly, to decide whether pyruvate metabolism is inherent in the sperm cells themselves and dependent upon the integrity of the sperm cell structure, the following two experiments were carried out. In one, spermatozoa that had been washed and resuspended in Ringer-phosphate were separated by centrifugation from the suspending medium, and both the sperm fraction and the supernatant were examined for their ability to metabolize pyruvate during anaerobic incubation. It was found that the metabolism of pyruvate was attributable exclusively to the spermatozoa, as no activity whatsoever was detectable in the supernatant fluid. In the other experiment, intact spermatozoa were compared with spermatozoa disrupted by sonication; as shown in Table 2, the ability of the latter to metabolize was greatly reduced as a result of structural damage.

\section{Lactate as major product of anaerobic metabolism of pyruvate by boar spermatozoa}

As shown in Table 1, lactate was the major product of the anaerobic metabolism of pyruvate. Table 1 also shows that both the rate of pyruvate disappearance $\left(\mu \mathrm{mol} / 10^{9}\right.$ spermatozoa/hr) and the percentage of pyruvate converted to lactate varied markedly. When, however, the analyses were done at 15-min intervals, and not merely at the end of $1 \mathrm{hr}$, it was observed that the initially high ratio between pyruvate utilized and lactate accumulating did not remain constant but declined with time. As Text-fig. 1 shows, during the $2 \mathrm{nd} \mathrm{hr}$ 
of anaerobic incubation, pyruvate continued to be used up at a rate which was only slightly lower than during the first hour, while the amount of lactate accumulated at the end of $2 \mathrm{hr}$ did not rise much above that already present after the first hour.

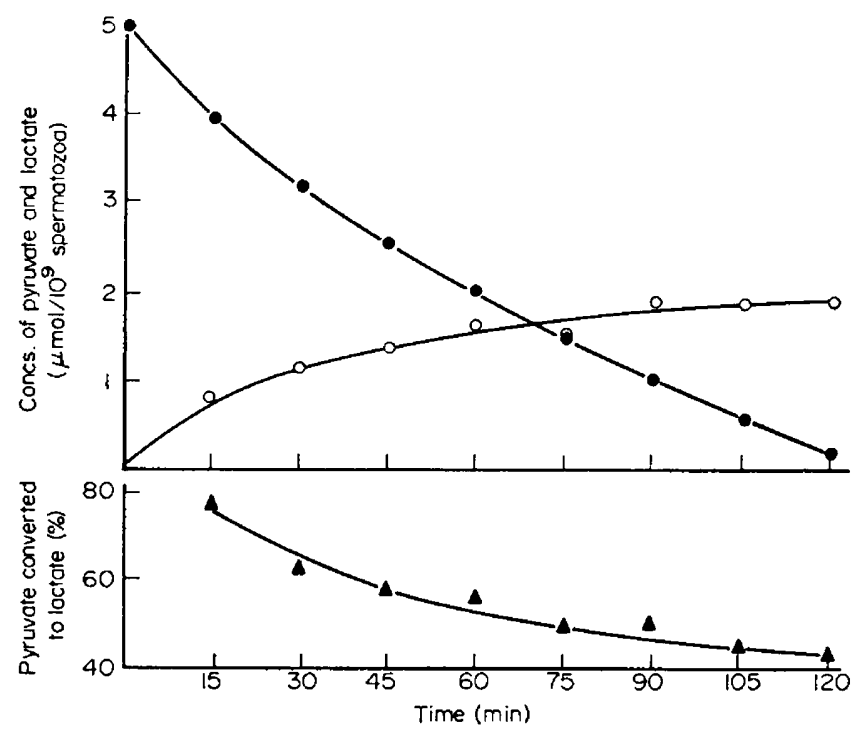

TEXT-FIG. 1. Time relationship between pyruvic acid utilized and lactic acid produced by a suspension of boar spermatozoa in Ringer-phosphate $\left(1.78 \times 10^{9} / \mathrm{ml}\right)$ during anaerobic incubation with pyruvate $(0.1 \%)$ at $25^{\circ} \mathrm{C}$. Concentrations of pyruvic acid (•) and lactic acid $(0)$, as determined in the incubation mixture ( $\mu \mathrm{mol} / 10^{9}$ spermatozoa). $\Delta$, Percentage of utilized pyruvic acid accounted for as lactic acid.

Acetate, succinate and acetoacetate as products of anaerobic metabolism of pyruvate by boar spermatozoa

The variable yields of lactate indicated that the simple stoichiometry of a dismutation of $2 \mathrm{~mol}$ pyruvate to $1 \mathrm{~mol}$ each of lactate, acetate and $\mathrm{CO}_{2}$, is not applicable to anaerobic pyruvate metabolism in boar spermatozoa. To explore the problem further, values for lactate were supplemented by determinations of acetate. Gas-liquid chromatography of volatile fatty acids separated by steam distillation from the incubation mixtures, showed that acetic acid is the main volatile acid produced anaerobically from pyruvic acid. However, the amount of acetate found was below that expected from a simple dismutation reaction (Table 1). It must also be added that exhaustively washed sperm suspensions, not incubated with pyruvate, yielded some acetate varying from 0.033 to $0.325 \mu \mathrm{mol}$ (mean value $0.18 \mu \mathrm{mol}$ ) $/ 10^{9}$ spermatozoa; acetate obtained in this way may be assumed to be derived from acetyl compounds of the boar spermatozoa.

The possibility that boar spermatozoa convert some pyruvic acid to organic acids other than lactic and acetic acid was next investigated. High-voltage electrophoresis was used to separate such acids. A washed sperm suspension was kept anaerobically for $1 \mathrm{hr}$ at $25^{\circ} \mathrm{C}$ with $0.1 \%$ pyruvate. The incubation 
was terminated by adding $1 / 10 \mathrm{vol} .25 \%(\mathrm{w} / \mathrm{v})$ metaphosphoric acid; $20 \mathrm{ml}$ of the acid extract was mixed with $80 \mathrm{~g}$ Celite 545, and the mixture was packed into a column and eluted with 2 litres of ether. The eluate was evaporated to dryness and the residue taken up in $1 \mathrm{ml}$ water. Aliquots of this solution subjected to electrophoresis at $\mathrm{pH} 4.0$ and 8.9 revealed the presence of a substance with the mobility characteristic of succinic acid. Succinic acid was then further identified by using succinic dehydrogenase. Text-figure 2 shows that oxygen consumption began immediately on adding $20 \mu \mathrm{l}$ of a soluble preparation of succinic dehydrogenase, and the rate doubled when a further $20 \mu \mathrm{l}$ of the enzyme were added subsequently. Malonate completely arrested the oxygen consumption. Confirmatory evidence for the identity of succinate was obtained by combined gas-liquid chromatography and mass spectrometry.

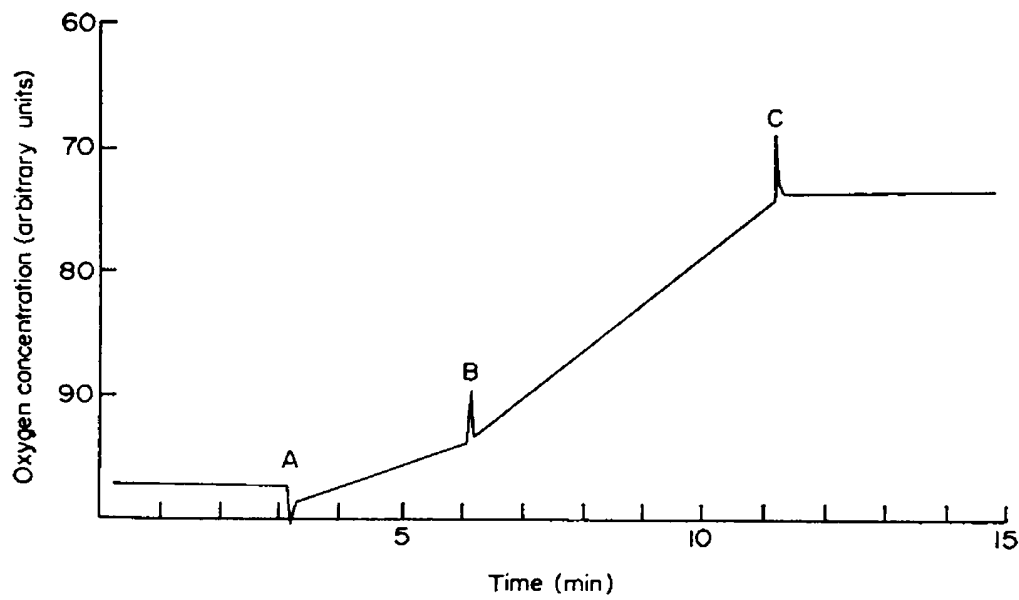

TexT-FIG. 2. Succinic dehydrogenase assay of succinate formed anaerobically from pyruvate by boar spermatozoa. Oxygen uptake was measured using an oxygen electrode connected to a recorder set in such a way that the position 100 on the scale corresponded to the point of complete saturation with oxygen at $25^{\circ} \mathrm{C}$, and the position 0 corresponded to an oxygen tension of zero. The assay mixture consisted of $1 \mathrm{ml} 0.1 \mathrm{M}$-potassium phosphate, $\mathrm{pH} 7 \cdot 5,+25 \mu \mathrm{l}$ phenazine methosulphate $(4 \mathrm{mg} / \mathrm{ml})+100 \mu \mathrm{l}$ of the extract from the spermatozoa-pyruvate incubation mixture. Purified succinic dehydrogenase $(20 \mu \mathrm{l})$ was added at $\mathrm{A}$ and $\mathrm{B} ; 15 \mu \mathrm{l}$-sodium malonate was added at $\mathrm{C}$. In the absence of the extract from the sperm-pyruvate incubation mixture, the assay system consumed no oxygen after addition of succinic dehydrogenase.

Having identified succinate, we proceeded to determine it quantitatively by means of gas-liquid chromatography. The results of these determinations (Table 1) showed that succinate accounts for only a small proportion of the pyruvate anaerobically metabolized by boar spermatozoa.

Gas-liquid chromatography of methylated organic acids was also used to identify and determine other products of pyruvate metabolism. However, none of the intermediaries of the tricarboxylic acid cycle was found to accumulate as a result of pyruvate metabolism. The absence of citrate, malate and 2-oxoglutarate was confirmed by using enzymatic and colorimetric methods of determination; it was also not possible to detect by means of these methods the formation of either acetoin, diacetyl, fructose or glucose. However, in a single 
sample containing ether-extractable methylated material, gas-liquid chromatography revealed the presence of a substance with a retention time corresponding to either methylacetoacetate or methyl-3-hydroxybutyrate. Subsequently, examination by enzymatic methods led to the identification of acetoacetate as a product of pyruvate metabolism in boar spermatozoa. However, like succinate, acetoacetate accounted for only a small proportion of the pyruvate used up (Table 1). When the anaerobic incubations were repeated using boar spermatozoa without pyruvate, no trace of either succinate or acetoacetate could be detected.

\section{Comparison of anaerobic and aerobic metabolism of pyruvate by boar spermatozoa}

Production of $\mathrm{CO}_{2}$ from pyruvate in sperm suspensions was estimated by measuring the production of ${ }^{14} \mathrm{CO}_{2}$ from carrier pyruvate mixed with either $\left[1-\mathrm{C}^{14}\right]-$ or $\left[2-\mathrm{C}^{14}\right]$ pyruvate. A comparison was made between anaerobic and aerobic conditions at 25 and $37^{\circ} \mathrm{C}$. Measurements of the pyruvate utilized, lactate produced and $\mathrm{CO}_{2}$ evolved, enabled calculation of the percentage conversion of pyruvate to lactate and $\mathrm{CO}_{2}$ (Table 3).

Table 3. Anaerobic and aerobic formation of ${ }^{14} \mathrm{CO}_{2}$ from $\left[1-{ }^{14} \mathrm{C}\right]$ - and $\left[2-{ }^{14} \mathrm{C}\right]$ pyruvate by boar spermatozoa

\begin{tabular}{l|c|c|c}
\hline \multirow{2}{*}{$\begin{array}{c}\text { Conditions of } \\
\text { incubation }\end{array}$} & \multicolumn{2}{|c|}{$\begin{array}{c}\% \text { pyruvate } \\
\text { converted to }{ }^{14} \mathrm{CO}_{2}\end{array}$} & $\begin{array}{c}\% \text { pyruvate } \\
\text { converted to lactate }\end{array}$ \\
\cline { 2 - 3 } & {$\left[1-{ }^{14} \mathrm{C}\right]$ pyruvate } & {$\left[2-{ }^{14} \mathrm{C}\right]$ pyruvate } & \\
\hline Anaerobic, $25^{\circ} \mathrm{G}$ & 25 & 2 & 64 \\
Aerobic, $25^{\circ} \mathrm{C}$ & 22 & 5 & 79 \\
Anaerobic, $37^{\circ} \mathrm{C}$ & 19 & 1 & 69 \\
Aerobic, $37^{\circ} \mathrm{C}^{*}$ & 16 & 8 & 68 \\
\hline
\end{tabular}

Suspensions of washed boar spermatozoa were incubated for $45 \mathrm{~min}$ with $0.25 \%$ non-labelled (carrier) sodium pyruvate in combination with either $\left[1-{ }^{14} \mathrm{C}\right]$ - or $\left[2-{ }^{14} \mathrm{C}\right]$ pyruvate.

* At the end of 45-min incubation, all of the pyruvate had disappeared.

Anaerobically, some $\mathrm{CO}_{2}$ was produced from the first carbon position (carboxyl group) but almost none from the second; oxidation of the second carbon atom was higher than it was anaerobically. The low values for $\mathrm{CO}_{2}$ production from the second carbon atom indicate that very little pyruvate was metabolized by way of the tricarboxylic acid cycle. Where the aerobic metabolism differed most prominently from the anaerobic one, was in respect of the ratio between pyruvate utilized and lactate accumulated. In each of a series of eight incubation experiments performed at $25^{\circ} \mathrm{C}$, where pyruvate utilization and lactate formation were measured simultaneously in the presence as well as absence of air, more pyruvate disappeared aerobically than anaerobically, and a higher percentage of it was accounted for as lactate (Table 4).

Concerning the products of aerobic utilization of pyruvate by boar spermatozoa, the two that could be identified with certainty were lactate and $\mathrm{CO}_{2}$; of the three other anaerobic metabolites of pyruvate, namely, acetate, succinate and acetoacetate, none was found in the presence of oxygen. This led us to 
explore the possibility that certain metabolites do not accumulate aerobically because, once formed, they are immediately broken down further. We have studied this point using acetoacetate. A suspension of spermatozoa in Ringerphosphate was first incubated with pyruvate anaerobically, and its acetoacetate content determined after $1 \mathrm{hr}$ at $37^{\circ} \mathrm{C}$. Next, it was shaken aerobically for another hour at $37^{\circ} \mathrm{C}$, and its acetoacetate content again determined. Two samples were run simultaneously as controls, one containing the sperm suspension without pyruvate, and the other with acetoacetate in the absence of spermatozoa.

Table 4. Comparison of pyruvate utilization and lactate formation by boar spermatozoa at $25^{\circ} \mathrm{C}$, under anaerobic and aerobic conditions

\begin{tabular}{l|l|l}
\hline & \multicolumn{2}{|c}{ Incubation } \\
\cline { 2 - 3 } & \multicolumn{1}{|c}{ Anaerobic } & \multicolumn{1}{|c}{ Aerobic } \\
\hline Pyruvate utilized & & \\
$\quad$ Mean & $4.03(0.43)$ & $5.91(0.72)$ \\
$\quad$ Range & $2 \cdot 14$ to 5.95 & $2 \cdot 74$ to $8 \cdot 40$ \\
Lactate produced & & \\
$\quad$ Mean & $2.35(0.32)$ & $4.31(0.67)$ \\
$\quad$ Range & 0.86 to 3.83 & 1.44 to 7.13 \\
Percentage of pyruvate converted to lactate & $57.0(3.3)$ & $70.6(3.7)$ \\
Mean & & \\
Range & 40.0 to 70.9 & 52.6 to 84.8 \\
\hline
\end{tabular}

Results ( $\mu \mathrm{mol} / 10^{9}$ spermatozoa $/ \mathrm{hr}$ ) are expressed as mean values from eight experiments (S.E.M. in parentheses). A $t$ test for the comparison of anaerobic and aerobic values was significant at the $5 \%$ level for all three parameters.

No acetoacetate was produced by spermatozoa, either anaerobically or aerobically in the absence of pyruvate. In the presence of pyruvate, $0.357 \mu \mathrm{mol}$ acetoacetate $/ 10^{9}$ spermatozoa accumulated at the end of $1 \mathrm{hr}$ anaerobic incubation, but when this was followed by aerobic incubation, the concentration of acetoacetate decreased by only $18 \%$; in the control sample with acetoacetate alone, the concentration decreased by $5 \%$. These results indicated that only $13 \%$ of the acetoacetate produced anaerobically from pyruvate disappears following a change from anaerobic to aerobic conditions.

\section{DISCUSSION}

In order to sustain flagellar movements, mammalian spermatozoa utilize exogenous substrates, including fructose, the sugar characteristic of seminal plasma. The rate of fructolysis, of which pyruvate is an intermediary and lactate the end product, shows a remarkably close relation to the degree of motility: any treatment, such as 'cold shock', which immobilizes spermatozoa completely and irreversibly, at the same time largely deprives them of the ability to utilize fructose (Mann \& Lutwak-Mann, 1955; Mann, 1964). However, as demonstrated in this study, the final stage of fructolysis, i.e. the NAD-dependent reduction of pyruvate to lactate, can proceed in motile as well as in cold-shocked, immobilized spermatozoa. This particular step is, therefore, not directly bound 
up with sperm motility. It was also shown recently that, although cold shock abolishes motility, this loss does not result in a great decrease in the intracellular content of NAD in spermatozoa (Brooks \& Mann, 1972). Herein probably lies the explanation of why pyruvate metabolism can continue in immobilized spermatozoa. On the other hand, when the structure of the sperm cell is mechanically disrupted and NAD lost, pyruvate metabolism declines.

\section{Anaerobic metabolism of pyruvate}

Under anaerobic conditions, the rate of pyruvate utilization by boar spermatozoa is considerably higher than that of fructose utilization. Unlike the situation in anaerobic fructolysis, however, where lactate accounts for most, if not all, of the fructose used up, the yield of lactate produced from pyruvate as the sole substrate accounts for only about $50 \%$ of pyruvate used up. The simplest explanation for these results would be that in boar spermatozoa, the anaerobic metabolism of pyruvate follows the course of a dismutation, in which two molecules of pyruvate interact with each other in such a way that one is reduced to lactate, while at the same time the other undergoes an oxidation to acetate and $\mathrm{CO}_{2}$. However, our study showed that the ratio between pyruvate and its metabolites does not fit into the stoichiometry of a simple dismutation. Even under experimental conditions where approximately $50 \%$ of the utilized pyruvate appeared as lactate, the quantities of acetate and $\mathrm{CO}_{2}$ were consistently less than required by a simple dismutation. A closer examination of the ratio of pyruvate utilized to lactate produced indicated, moreover, that it does not stay constant but declines with time. This suggested to us that lactate, acetate and $\mathrm{CO}_{2}$ are not the sole products of anaerobic metabolism of pyruvate. Using various methods, we were able to identify with certainty at least two more anaerobic metabolites, namely, succinate and acetoacetate. However, even the combined yields of all these metabolites did not add up to $50 \%$ of pyruvate used up. The pyruvate unaccounted for is presumably converted to one or more as yet unidentified products.

Acetoin, diacetyl, fructose, glucose, citrate, malate, 2-oxoglutarate, oxaloacetate and 3-hydroxybutyrate could all be excluded as final products of pyruvate metabolism. The possibility remains that some of the pyruvate may have undergone either transamination to alanine, or conversion to some acidic, alcoholic, aldehydic or phosphorylated compound. Transamination would be in line with the high transaminase activity characteristic of spermatozoa in both bull and boar (Flipse \& Anderson, 1959; Flipse, 1960; van der Horst, 1970). But our observations with labelled pyruvate show that less than $10 \%$ of the radioactivity resulting from utilized pyruvate was present in the residue from ether extraction of the acid-treated spermatozoa-pyruvate incubation mixtures. Since amino acids are not ether-extractable under such conditions, it seems unlikely that in our experiments transamination could have played a major rôle.

As regards the anaerobic formation of succinate, in order to convert pyruvate to succinate, the spermatozoa must presumably form oxaloacetate first, a mechanism which would fit in with the recognized ability of the sperm cells to fix carbon dioxide (Mann, 1964; O'Shea \& Wales, 1967, 1970; Mounib \& Eisan, 1968). Although significant amounts of acetoacetate were produced by 
spermatozoa anaerobically, we failed to detect any 3-hydroxybutyrate in the spermatozoa-pyruvate incubation mixtures, notwithstanding the fact that the equilibrium in the reaction controlled by 3-hydroxybutyric dehydrogenase would be expected to favour such a course (Krebs, Mellanby \& Williamson, 1962). We also know that 3-hydroxybutyrate, in common with acetoacetate, does not alter the oxidation state of NAD in boar spermatozoa under anaerobic conditions, nor does it influence the rate of sperm respiration (Brooks \& Mann, 1972). It seems unlikely, therefore, that the spermatozoa of the boar, in contrast to those of the ram, either possess 3-hydroxybutyrate dehydrogenase or employ a catabolic pathway for utilizing acetoacetate. They are nevertheless capable of forming acetoacetate, perhaps by means of a mechanism akin to the one that has been proposed for the liver, involving first, a condensation of two molecules of acetyl-CoA to form acetoacetyl-CoA; next, another condensation with acetyl-CoA, leading to 3-hydroxy-3-methylglutaryl-CoA; and finally, an enzymatic cleavage to acetyl-CoA and acetoacetate (Lynen, Wessely, Wieland \& Rueff, 1952; Lynen, Henning, Bublitz, Sörbo \& Kröplin-Rueff, 1958).

\section{Aerobic metabolism of pyruvate}

A comparative study of the anaerobic and aerobic metabolism of pyruvate helped to bring out a number of facts relating to boar spermatozoa: (a) both the rate of pyruvate disappearance and the percentage of pyruvate converted to lactate were higher aerobically than anaerobically; (b) lactate and $\mathrm{CO}_{2}$ were the main aerobic metabolites, but acetate, acetoacetate and succinate were absent; and (c) the production of $\mathrm{CO}_{2}$ from $\left[2-{ }^{14} \mathrm{C}\right]$ pyruvate was only a little higher aerobically than anaerobically, indicating that little of the aerobic metabolism of pyruvate was attributable to reactions associated with the tricarboxylic acid cycle.

The absence of acetate, succinate and acetoacetate as aerobic products, could be explained by assuming that all three substances are, in fact, formed aerobically just as anaerobically, but are rapidly disposed of in the presence of oxygen. This might apply to acetate and partly also to succinate which are both known to exert an enhancing effect on the respiration of boar spermatozoa (Brooks \& Mann, 1972). Since, however, acetoacetate is not oxidized by spermatozoa to any appreciable extent, it seems more likely that it is not formed aerobically at all, perhaps because in the presence of oxygen, acetyl-CoA is used in the reactions associated with the tricarboxylic acid cycle, rather than for the purpose of acetoacetate production.

\section{ACKNOWLEDGMENTS}

We gratefully acknowledge the help received from $\mathrm{Dr}$ R. A. P. Harrison, Mr A. Karagiannidis, Mr R. Self, Dr P. F. V. Ward and Miss W. Butler.

\section{REFERENCES}

Aalbers, J. G., Mann, T. \& Polge, C. (1961) Metabolism of boar semen in relation to sperm motility and survival. J. Reprod. Fert. 2, 42. 
Barker, S. B. \& Summerson, W. H. (1941) The colorimetric determination of lactic acid in biological material. F. biol. Chem. 138, 535.

Bernath, P. \& Singer, T. P. (1962) Succinic dehydrogenase. In: Methods in Enzymology, Vol. 5, p. 605. Eds. S. P. Colowick and N. O. Kaplan. Academic Press, London and New York.

Bishop, M. W. H., Gampbell, R. G., Hancock, J. L. \& Walton, A. (1954) Semen characteristics and fertility in the bull. F. agric. Sci., Camb. 44, 227.

Brooks, D. E. \& MANN, T. (1972) Relation between the oxidation state of nicotinamide adenine dinucleotide and the metabolism of spermatozoa. Biochem. F. 129, 1023.

FLIPSE, R. J. (1960) Metabolism of bovine semen. IX. Glutamic-oxaloacetic and glutamic-pyruvic transaminase activities. F. Dairy Sci. 43, 773.

Flipse, R. J. \& AlmQuist, J. O. (1955) Metabolism of bovine semen. II. Qualitative anaerobic catabolism of glucose-C ${ }^{14}$ by bovine spermatozoa. F. Dairy Sci. 38, 782 .

Flipse, R. J. \& Anderson, W. R. (1959) Metabolism of bovine semen. VII. Pyruvate-alanine conversion. F. Dairy Sci. 42, 637.

Friedemann, T. E. \& Haugen, G. E. (1943) Pyruvic acid. II. The determination of keto acids in blood and urine. F. biol. Chem. 147, 415 .

Glover, T. \& Mann, T. (1954) On the composition of boar semen. F. agric. Sci., Camb. 44, 355.

Graves, C. N., Lodge, J. R. \& Salisbury, G. W. (1966) Metabolic end products of anaerobic spermatozoan metabolism. Nature, Lond. 211, 308.

Gross, D. (1958) Separation of the lower fatty acids $\left(\mathrm{C}_{1}\right.$ to $\left.\mathrm{C}_{10}\right)$ by high-voltage paper electrophoresis. Nature, Lond. 181, 264.

Harrison, R. A. P. \& White, I. G. (1972) Glycolytic enzymes in the spermatozoa and cytoplasmic droplets of bull, boar and ram, and their leakage after shock. F. Reprod. Fert. 30, 105.

Jeffay, H. \& Alvarez, J. (1961) Liquid scintillation counting of carbon-14. Use of ethanolamineethylene glycol monomethyl ether-toluene. Analyt. Chem. 33, 612.

Korkes, S., del Gampillo, A., Gunsalus, I. G. \& Ochoa, S. (1951) Enzymatic synthesis of citric acid IV. Pyruvate as acetyl donor. 7. biol. Chem. 193, 721.

Krebs, H. A. \& Johnson, W. A. (1937) Metabolism of ketonic acids in animal tissues. Biochem. F. 31, 645.

KRebs, H. A., Mellanby, J. \& Williamson, D. H. (1962) The equilibrium constant of the $\beta$-hydroxybutyric-dehydrogenase system. Biochem. 7. 82, 96.

Lynen, F., Henning,U., Bublttz, C., SöRbo, B. \& KRöplin-RuefF, L. (1958) Der chemische Mechanismus der Acetessigsäurebildung in der Leber. Biochem. Z. 330, 269.

Lynen, F., Wessely, L., Wieland, O. \& RUEFF, L. (1952) Zur B-Oxydation der Fettsäuren. Angew. Chem. 64, 687.

Mann, T. (1948) Fructose content and fructolysis in semen. Practical application in evaluation of semen quality. F. agric. Sci., Camb. 38, 323.

ManN, T. (1964) The biochemistry of semen and of the male reproductive tract. Methuen, London.

MANN, T. \& LUTWAK-MANN, C. (1955) Biological changes underlying the phenomenon of cold shock in spermatozoa. Archo. Sci. biol. 39, 578.

MARKhaM, R. (1942) A steam distillation apparatus suitable for micro-Kjeldahl analysis. Biochem. 7 . 36, 790.

Melrose, D. R. \& Terner, G. (1953) The metabolism of pyruvate in bull spermatozoa. Biochem. $\mathcal{F}$. $53,296$.

MoRley, G., DAwson, A. \& MARKs, V. (1968) Manual and autoanalyzer methods for measuring blood glucose using guaiacum and glucose oxidase. Proc. Ass. clin. Biochemists, 5, 42.

Mounis, M. S. \& EisAN, J. S. (1968) Metabolism of pyruvate and glyoxylate by eggs of salmon (Salmo salar). Comp. Biochem. Physiol. 25, 703.

Nevo, A. G., Polge, C. \& Frederick, G. (1970) Aerobic and anaerobic metabolism of boar spermatozoa in relation to their motility. F. Reprod. Fert. 22, 109.

O'Shea, T. \& Wales, R. G. (1967) Fixation of carbon dioxide by ram spermatozoa. F. Reprod. Fert. 14, 333.

O'Shea, T. \& Wales, R. G. (1970) Studies of the fixation of carbon dioxide by washed ram spermatozoa. Aust. F. biol. Sci. 23, 889.

Perlman, D., Lardy, H. A. \& Johnson, M. J. (1944) Determination of citric acid in fermentation media and biological materials. Ind. Engng Chem. analyt. Edn, 16, 515 .

RoE, J. H. (1934) A colorimetric method for the determination of fructose in blood and urine. $\mathcal{J}$. biol. Chem. 107, 15.

Roper, R. \& MA, T. S. (1957) Diazomethane as a reagent for microsynthesis. Microchem. 7. 1, 245.

ROTHSCHILD, LORD (1964) Anaerobic fructolysis, lactic acid and heat production of bull spermatozoa. Proc. R. Soc. B, 159, 291.

Scott, T. W., Voglmayr, J. K. \& Setchell, B. P. (1967) Lipid composition and metabolism in testicular and ejaculated ram spermatozoa. Biochem. F. 102, 456. 
TERner, C. (1962) Oxidative and biosynthetic reactions in spermatozoa. In: Spermatozoan Motility, p. 89. Ed. D. W. Bishop. American Association for the Advancement of Science, Washington, D.C.

VAN DER HORst, C. J. G. (1970) The occurrence of phenylalanine- and $\alpha$-aminocaprylic acid- $\alpha$ ketoglutarate transaminase in boar spermatozoa. Experientia, 26, 249.

WAlEs, R. G. \& Humphries, E. J. (1969) The intracellular accumulation of metabolites by ram spermatozoa during incubation in the presence of exogenous fructose. Aust. F. biol. Sci. 22, 1005.

Westerfeld, W. W. (1945) A colorimetric determination of blood acetoin. 7. biol. Chem. 161, 495.

Williamson, D. H., MellanBy, J. \& KreBs, H. A. (1962) Enzymatic determination of D(-)- $\beta$-hydroxybutyric acid and acetoacetic acid in blood. Biochem. F. 82, 90 . 